G. Ginda, D. Dawiec, AGH University of Science and Technology, Faculty of Management, Cracow, Poland \{ gginda@zarz.agh.edu.pl ; domiwos@agh.edu.pl \}

\title{
SMART CITY PRINCIPLE-BASED ENERGY SOLUTION EVALUATION FRAMEWORK
}

\begin{abstract}
Smart city is a general concept for sustainable development of a contemporary city while taking advantage of population creativity and capability for innovations as well as existing institutions, procedures, and infrastructure. It provides foundations for fulfilling requirements of six basic implementation fields that deal with intelligent economy, mobility, environment, people, living, and governance, respectively. Therefore, the fields seem to provide apparent foundation for a comprehensive and sustainability-aware evaluation of actual solutions implementing smart city concept. This is why a general framework for such evaluation is discussed in the paper. Particular framework implementation is also presented. It is based on the use of two decision support techniques, namely DEMATEL and ANP. A sample application is also presented to illustrate merits of the framework.
\end{abstract}

Keywords: ANP, DEMATEL, application, smart city, energy policy, decision, support.

\section{Introduction}

Smart city is a relatively new and concept of urban space development. It was developed in the end of the last century (Shetty, 1997) and becomes more and more popular. For example, Scopus bibliographic database query returns information about almost 8,500 thousands publications while answering 'smart city' query. Smart city comes from a more general concept of a sustainable city. Actually, the concepts differ in philosophy. Sustainable city concept deals with sustainability goals achievement while smart (sustainable) city rather deals with concrete targets.

Smart city proposes a general comprehensive framework for contemporary city development. Its implementation is based on the effective application of 4 components (Komninos, 2009):

1. Creative population capable of intensive knowledge utilization.

2. Institutions and procedures that provide effective means for the creation of knowledge sources and facilitate knowledge acquiring, adoption, and development.

3. Developed broadband communication infrastructure that provide digital service spaces and web applications for knowledge management.

4. The capability of delivering the innovative solutions for unique problems.

Complexity of contemporary urban environments results in special attention in smart city concept drawn towards some principal dimensions of city development. The following six principal dimensions are mostly dealt with:

1. Smart economy (SE).

2. Smart mobility (SM).

3. Smart environment (SN).

4. Smart people (SP). 
5. Smart living (SL).

6. Smart governance (SG).

Smart economy aims at rising multi-dimensional productivity, innovation, and work market flexibility. Smart mobility provides necessary means for effective transportation and information interchange. Smart environment aims at a sustainable usage of available resources. Smart people dimension deals with continuous development in life quality by means of city changes initialized by self-engaged citizens. Smart living provides friendly environment for the citizens. Smart governance is devoted to the development of appropriate city management system. Note that although other dimensions are sometimes recalled e.g. smart health (Cuzzocrea et al, 2018) that pertains to healthcare management, they are utilized rather occasionally for the peculiar purposes.

\section{Evaluation of smart city solutions}

Researchers indentify are several smart city concept-related gaps in smart city research and practice. Some of the gaps deal with reliable smart city-related assessment. For example, Bibri \& Krogstie (2017) identify the following gaps:

- a lack of frameworks for the classification and ranking of smart cities according to their contribution to sustainability,

- a lack of assessment framework for measuring how smartness and sustainability in cities enhance each other,

- a lack of a common conceptual framework for comparing the evolving models of smart cities and planning proposals,

- a lack of a reliable theory for the comparison of potential models of smart city models and for the evaluation of an extent to which a smart city model contributes to achieving sustainability goals and smartness targets,

- a lack of frameworks for combining the typologies and design concepts of sustainable urban forms with smart methods for the assessment of their practicality in the context of contribution to sustainability,

- a lack of normative prescriptions for achieving the status of smart city and for developing assessment frameworks for measuring and improving such status.

The above mentioned gaps are addressed by the proposal of a general evaluating framework for smart cities which is discussed in the paper.

\section{Assessment framework proposal}

It seems that the importance of principal fields for smart city implementation make them appropriate means for the reliable evaluation of solutions that implement smart city concept. Therefore, they are finally applied in proposed general assessment framework. The framework is illustrated in Fig.1.

Note that because of to the availability of numerous evaluation approaches the proposed general framework may be implemented in diverse ways. For example, Political, Economic, Socio-cultural and Technological (PEST) analysis (Al-Rafai, 2002) or a well known Strengths, Weaknesses, Opportunities, and Risks (SWOT) analysis may be applied in this regard. It is also possible to utilize achievements of multi-attribute decision making to implement the assessment framework by means of a dedicated and flexible approach for the evaluation of smart city implementation measures. The application of DEMATEL and ANP is finally proposed in this regard.

International Symposium on

the Analytic Hierarchy

Process
2

Hong Kong, HK.

July 13 - July 15, 2018 
SE, SM, SN, SP, SL, SG weight estimation

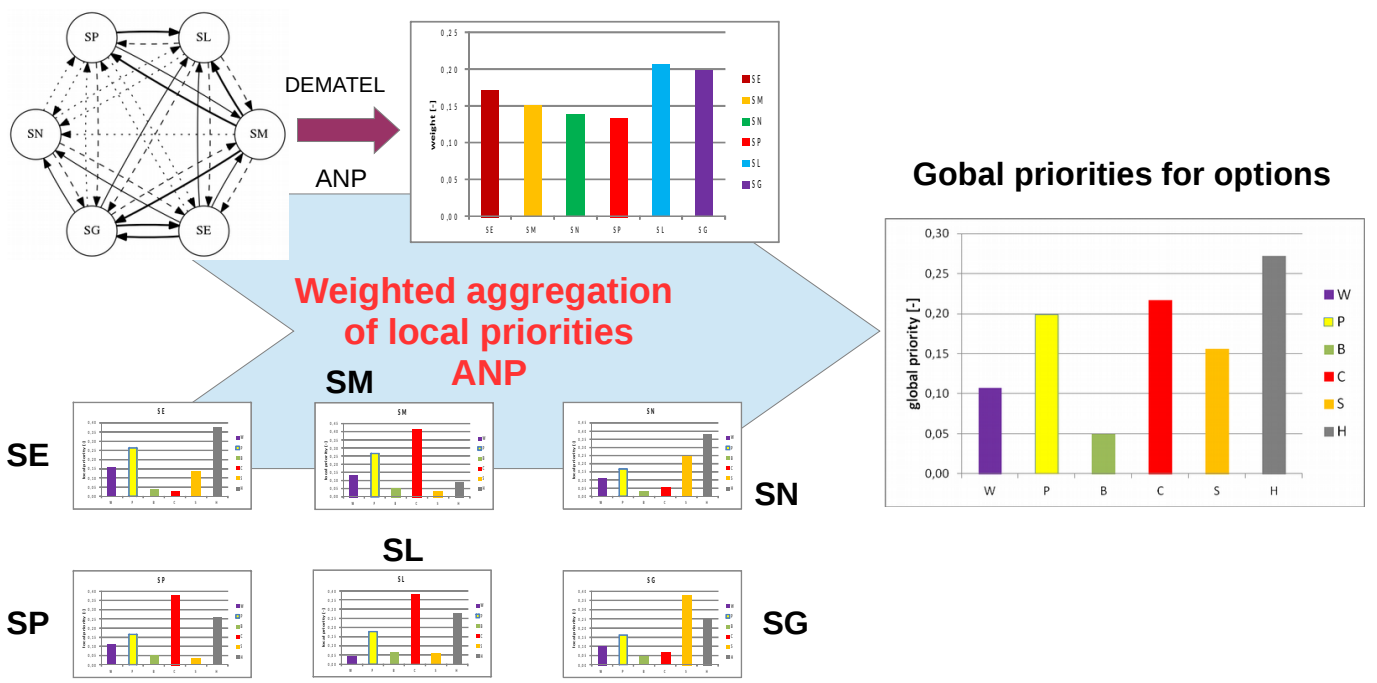

Estimation of local priorities for options

Figure 1. Sample DEMATEL and ANP-based implementation of proposed framework

DEMATEL provides information about possible inter-relations between assessment criteria - smart city concept dimensions - to help to structure a dedicated ANP control net. ANP delivers then necessary means for prioritizing assessment criteria and considered smart city solutions (see: Fig.1).

\section{Sample application of the framework}

Sustainability-awareness and comprehensiveness of smart city results in a need for dealing with diverse application areas. Some of them are nevertheless exceptionally important for achieving principal smart city implementation targets. Energy management is undoubtedly one of them. This is mainly because it deals with several fields at once e.g. productivity (smart economy), dispersed energy production and consumption (smart mobility), sustainability in resource management and intelligent optimization of energy consumption while reducing harmful emissions to natural environment (smart environment), energy security providing (smart living) as well as a need for holistic energy management (smart development). Energy management-related sample analysis is applied, therefore, to illustrate the usefulness of evaluating framework proposal. The identification of the most appropriate way for renewable energy acquisition is utilized in this regard.

Let's consider the case of six candidate technologies that are capable of distributed energy generation at power level of $10 \mathrm{~kW}$ or less. Considered technology options include:

1. Small wind power plants (W).

2. Photo-voltaic modules (P).

3. Biogas and biofluids (B).

4. Micro co-generation (C).

5. Solar thermal collectors (S).

6. Heat pumps $(\mathrm{H})$. 


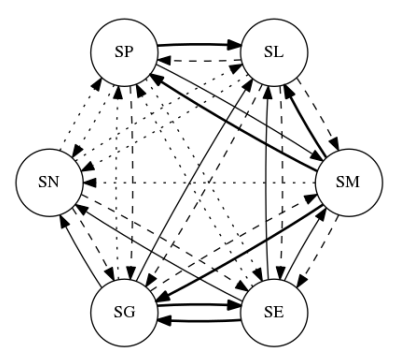

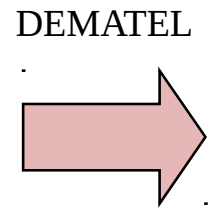

ANP

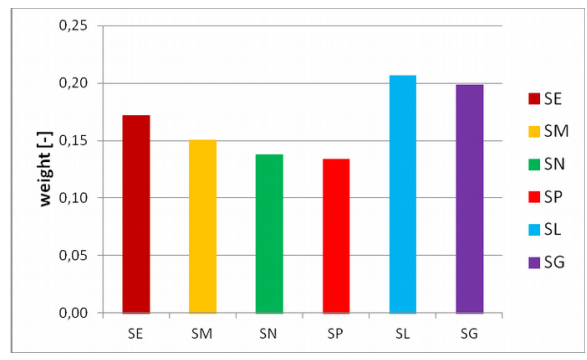

Figure 2. Estimation of assessment criteria weights
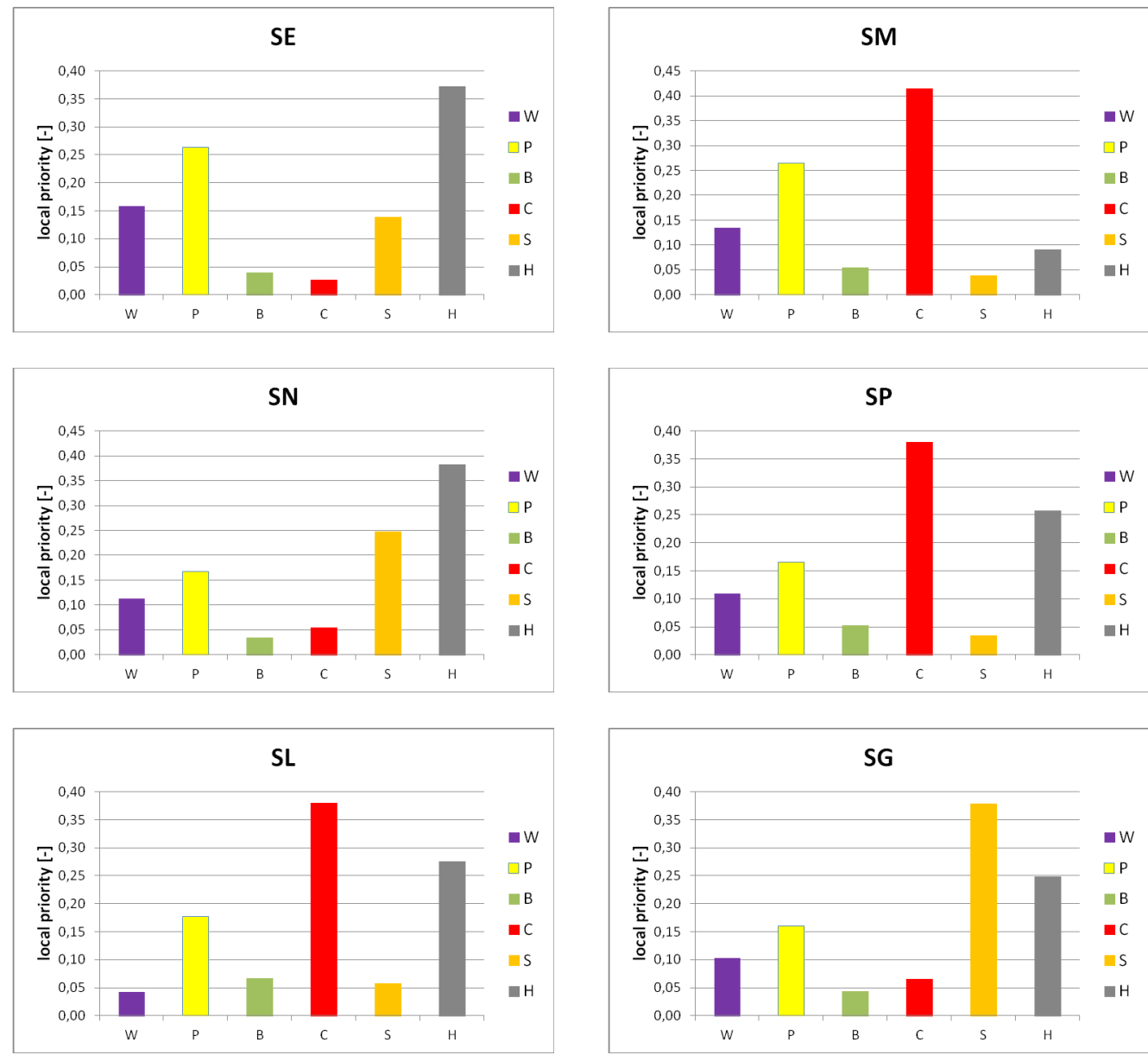

Figure 3. Local priorities for options

Information about the options and direct relations between assessment smart city concept-based criteria were articulated by means of expert opinions. Local Polish conditions were taken into consideration with this regard. Fig.2 shows assumed structure of direct influence relations between assessment criteria (left side) and resulting weights obtained for the criteria (right side). Note that 0-4 DEMATEL direct influence scale was applied. Scale levels are expressed by line patterns (from 1 - dotted line to 4 - bold line). 
Fig.3 illustrates local priorities obtained for technology options. Final results are presented in Fig.4. It turns out that heat pumps is clearly the best option. Local priorities testify that strong position of heat pumps option may be endangered by micro co-generation option only. Photo-voltaic modules, solar thermal collectors and small wind power plants options occupy the third, the fourth and the fifth rank, respectively. Biogas and biofuels is clearly the worst option according to applied expert opinions.

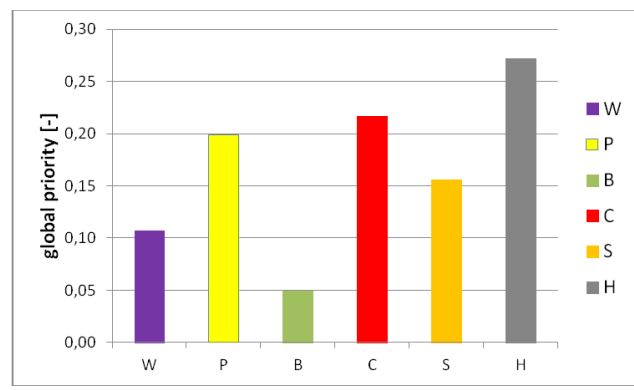

Figure 4. Final results

\section{Conclusions}

Smart city concept deals with a holistic city development. This is why means applied to implement the concept are assessed with regard to their performance in specific dimensions. The dimensions seem to be appropriate criteria for the reliable assessment of the smart city concept implementation means. They are utilized, therefore, in a general assessment framework for such means that is presented in the paper. Note that the components of dimensions may be also easily included in the framework.

The framework is implemented in the paper by using acknowledged decision support tools, namely: ANP and DEMATEL to cope with complexity of smart city implementation issues in a reliable manner. Results obtained for sample application of the implementation confirm its possible usefulness. Note that both techniques provide numerous possibilities that would foster and facilitate further development of the framework. Finally, software implementation of the framework is also intended to provide smart city concept implementers and other stakeholders with appropriate means for dealing with complexity of real-life problems in a trustful way.

\section{Key References}

Shetty, V. (1997). A tale of smart cities, Communications International (London), 24 (8), 16.

Komninos, N. (2009). Intelligent Cities and Globalisation of Innovation Networks, Routledge, London and New York.

Cuzzocrea, A., Ferri, F., Grifoni, P. (2018). Intelligent sensor data fusion for supporting advanced smart health processes. Advances in Intelligent Systems and Computing, 611, 361-370.

Bibri, S.E., Krogstie, J. (2017). Smart sustainable cities of the future: An extensive interdisciplinary literature review. Sustainable Cities and Society, 31, pp. 183-212.

Al-Rafai, W. (2002). Designing and operating pipeline infrastructure to achieve security of supply and safety. Pipeline and Gas Journal, 229(7), 37. 
G. Ginda, D. Dawiec: SMART CITY PRINCIPLE-BASED ENERGY SOLUTION EVALUATION

FRAMEWORK

\section{ACKNOWLEDGEMENTS}

Publication of the article was financed by the AGH University of Science and Technology, Cracow, Poland (subject subsidy for maintaining research potential). 